\title{
JUDGMENTS ON THE SEX OF HANDWRITING.
}

BY JUNE E. DOWNEY,

University of Wyoming.

In his book entitled Les révélations de l'écriture d'après un contrôle scientifique, Binet cites an investigation undertaken to decide whether it is possible to determine sex from handwriting. His conclusion is that within certain limits it is possible to do so. The question whether the sex-difference so discovered be due to psycho-physiological or social causes is left open.

It seemed to me worth while to repeat Binet's test in this country where, at least, the variation in writing induced by sex segregation in education would be minimized. A further motive for the test was furnished by the fact that the passing of such a simple judgment as 'man's writing' or 'woman's writing' seemed to offer particularly good material for a study of certain phases of judgment.

In the present test Binet's method was followed closely except in the particulars cited below. Briefly, his procedure was as follows. One hundred and eighty envelopes that had for the most part passed through the mails but from which all seals, headings and the like had been removed were submitted to two professional graphologists and to fifteen persons ignorant of the art of graphology. After a careful study of each superscriptic:a, the observer recorded his judgment as to the sex of the writer. Of the envelopes, eighty-nine had been addressed, either to Binet himself or to members of his family, by women; ninety-one had been addressed by men. As no selection had been made of envelopes to be used in the test the collection was held to be a representative one. Binet cites as a source of error the tendency to infer the sex of the writer from the sex of the person addressed.

This source of error was avoided in the investigation to be reported since all envelopes used were addressed to a woman. Two hundred envelopes were employed; all but four had 
passed through the mails. One hundred had been addressed by women; one hundred by men. A considerable number of the two hundred persons whose writing appears in the series are known to have been educated wholly in co-educational schools. One hundred and fifty of the envelopes were collected by Dr. Grace R. Hebard as secretary of the board of trustees at the University of Wyoming. These envelopes were all superscribed to Dr. Hebard at the same address. They were numbered by her in the order in which they were received so as to insure a chance grouping within the series. The other fifty envelopes were addressed to me or to my sisters. The writers represented in the series include a considerable number of grade teachers and of college and university professors, many business men and women, a few lawyers, doctors and ministers, a few society women and women of leisure, a few literary people. On the whole, the collection is representative, although the teaching profession is unduly conspicuous.

These two hundred envelopes were submitted to thirteen persons, each of whom recorded his judgment as to the sex of the writer who had addressed each envelope. Whenever the writing on an envelope was recognized the judgment was thrown out. For the most part, however, the possibility of such recognition was slight since a very great number of the envelopes had been addressed by strangers to the community. None of the thirteen persons made any pretense to skill in reading handwriting; none was acquainted with the particular claims of graphology. Some of them had had, however, much more extensive opportunity to observe varied forms of penmanship than had others. In age, the observers varied from fifteen years to something over fifty. Eight of the observers had had some slight training in psychological experimentation; the others, none at all. Beside these judgments on the complete series of two hundred, five other persons gave judgments on a series of one hundred envelopes.

If in such a series of judgments, where there are only two possibilities to choose from, the number of right judgments exceeds fifty per hundred, it is evident that something other 
than chance dictates the judgment. In every case in the present test, as in the French test likewise, the percentage made was sixty or over. The results, in fact, parallel closely those obtained by Binet. The percentages of right judgments given by ten of his observers (neither of the experts is included) ran as follows: $65.9,66.4,67,68,69,69.3,72.9,73,73,73^{1}$ The percentages made in the present test were as follows: 60 $(P), 60(C), 61.5(B), 64(P y), 66(C k), 66.5(A), 68(B h), 68.5$ $(R), 70(D), 70.5(S), 7$ 1.4 $(S n), 7$ I.5 $(C n), 77.5(R a)$.

Binet concludes that it is possible, with a certain percentage of error, to determine sex from handwriting. Obviously in estimating this error it is permissible to take the best record made by any observer. In the French test this record was made by the professional graphologist, M. Crépieux-Jamin, with $\mathbf{7 8 . 8}$ per cent. of correct judgments. ${ }^{2}$ Furthermore, it is of course possible, though hardly proper under the circumstances, to argue that greater natural facility and a better grounded science of graphology would reduce the percentage of error. For instance, $R a$, who made the record in my test, was allowed to review her errors in the first hundred judgments and then asked to repeat the test for the second hundred. Her percentage of correct judgments rose to 80 . In any case, however, the possibility of a considerable percentage of error makes the determination of sex from handwriting of problematic value where a high degree of certainty is required as in legal procedure.

It would be possible in certain ways to strengthen Binet's conservative conclusion as to the validity of judgments passed on so-called sex-differences in handwriting. In the present investigation, for example, I asked the observers to enter their judgments under the following rubrics : Confidence Great, Confidence Moderate, Confidence Slight, and Confidence None. II now the percentage of correct judgments be calculated from the number entered under the head of Confidence Great, we get the following figures in place of those given above: $66.3(B), 67.4$ $(C), 70.5(D), 70.9(B h), 72(A), 72.1(R), 72.7(C k), 80.1(C n)$,

'Les revelations de l'ecriture, p. 11.

$O p$. cit., p. 8. I am unable to get this percentage from Binet's figures. According to my reckoning the percentage should read 78.3 . 
81.1 $(R a), 82.4(S n), 82.9(P y), 83.3(S)$. The percentage of $P$ is not included since he failed to use the exact rubrics named in the instructions. In every case given it is evident that the percentage of error has been considerably reduced. Within a certain range the revelation of sex appears to be quite evident. Binet shows also that $M$. Crépieux-Jamin's percentage of correct judgments rose when this percentage is reckoned on the basis of the judgments that he considered certain in distinction from those that he considered only probable.' Under conditions most favorable to the expert, according to Binet's report, the error is reduced to ten per hundred.

Another fact emphasizing the validity of the judgments under investigation is brought out by a further study of the results of the present test. The judgments of the thirteen observers on the two hundred envelopes were tabulated in such a way as to show the concordance of judgments on the part of the observers. The judgments of twenty-one of the two hundred envelopes showed complete unanimity; in the case of forty-two other envelopes there was only one dissenting judgment, so that in sixty-three cases there was practical unanimity of judgment on the part of the observers. Further, in all but fifty cases there was a strong preponderance of judgments (four or more) in favor of one or the other of the sexes. Such facts show conclusively that there exists, for the average person, a fairly definite conception of masculine and feminine penmanship.

The bearing of the evidence upon the fact of actual sex-differences is, however, blurred by what Binet calls the inversion of sex signs. In my test, of the sixty-three envelopes on which judgment was practically at one, nine were written by the sex opposite to that to which they were ascribed. In the 150 cases showing a clear preponderance of judgments in one direction or the other, twenty-seven such inversions occur. Binet gives reproductions of writing showing inversion of sex signs but fails to state the number of times such inversions occur - an unfor-

1Op. cit., p. 9. I cannot determine from Binet's figures the percentage of correct judgments calculated from the number given with certainty. So far as I understand the figures the percentage is 82.3, closely approximating the best record made in my test. 
tunate omission which renders impossible a detailed comparison of his results with mine.

Again, examination of the present results shows something of which Binet makes no mention, namely, that these so-called inversions of sex signs occurred somewhat more frequently in the case of women than in the case of men; that is, the twentyseven cases of notable inversion include seventeen cases of women's writing uniformly ascribed to men and only ten cases in which the reverse occurred. Furthermore, the records show a distinct preponderance of masculine judgments. Of the 2,592 judgments passed I,35I were masculine, $I, 24 \mathrm{I}$ feminine. The reason for this excess of masculine judgments is evident from the statements of certain observers relative to what they considered to be the signs of masculinity and femininity in handwriting. Obviously, originality.is held to characterize the man's hand; conventionality, the woman's. Consequently, masculine handwriting is thought to show a more extensive range of variability than does the woman's. The plain evidence of such a constant drift in judgment is interesting in view of the fact that it follows the cunclusion of certain scientists that men are much less conventional than women and show a greater range of variability. In the present case such a pressure of social judgment (if one may so express it) led to a constant error.

In this connection it is profitable to study the handwriting uniformly. judged masculine or feminine. The typical feminine hand does appear to be colorless, conventional, neat and, usually, small. I should judge it unlike the feminine hand of the French test. In four cases alone does it exhibit individuality. Two of these four exceptions were graceful flowing hands; one an excessively rounded hand; one a backhand. Frequently this hand shows signs of unaccustomedness, that is, of being the handwriting of a person who had done no great amount of handwriting either because of youth or manner of life. Such unaccustomedness leads to conventionality in writing. This feminine hand is also in many of the cases the handwriting of grade or high-school teachers, whose profession emphasizes conventionality of writing. The typical man's hand is bold or 
careless or experienced, above all, individual. It is written by professional men and women or by newspaper and literary folk.

Let us now study the twenty-seven cases showing inversion of sex characteristics. The ten masculine writers of feminine handwriting were as follows: one farm hand, one college student, two school teachers, two college professors, one business man, one lawyer, one minister, one left-handed superintendent of public instruction. The first four wrote the colorless conventional, somewhat unaccustomed hand already described; the second five wrote small neat flowing hands; the tenth penman wrote a labored backhand. At least two of these men have done no great amount of writing; four others are teachers.

The seventeen women whose writing was judged masculine were as follows: three county superintendents of public instruction, one public lecturer, one university secretary, three women who have held clerical positions, one college professor, four school teachers, two society women, two old ladies of over seventy years, one of whom had served for years as a librarian. Of these women, seven wrote either very bold or very rapid hands; six wrote very individual hands; the other four wrote careless sprawling hands. The point to be noticed is that at least half of the number have been accustomed to more than a usual amount of handwriting. This fact would apparently lead to a social rather than a psycho-physiological interpretation of sex-differences in handwriting. A reversed interpretation is of course possible since it is open to argue that original mental differences are basal and that the inversion of sex signs in handwriting points to an inversion in other respects. The trend of my results makes me exceedingly doubtful of such an interpretation. Granting the existence of sex mental differences based on profound psycho-physiological causes, one would scarcely expect to find an inversion of such differences eighteen times per hundred cases.

In this connection it is well to note the hand called by Binet ambiguous. It gives.little evidence of sex. In the present test there were found twenty-one cases in which the judgments were practically evenly distributed between the two sexes. A study of the envelopes so grouped reveals in general two sorts of 
handwriting. The one is, again, the manifestly inexperienced hand; the other a small supple hand, less bold than the socalled masculine hand, more individual than the so-called feminine hand. This latter hand appears to be, frequently, the handwriting of highly cultured persons.

Attention should also be called to age as influencing handwriting. Naturally the unaccustomed, hence conventional and labored, hand would more frequently characterize the younger penmen, solely on the ground of lack of experience. The writers producing in the present test the typical woman's hand probably averaged less in age than did those writing the man's hand, although there were striking exceptions. CrépieuxJamin would ask that the handwriting of very old people be eliminated in a test on the revelation of sex in handwriting. It was evident that the very old ladies whose writing appeared in my series did not produce the typical woman's hand.

To sum up. From my analysis of my own results I conclude that it is possible to determine sex from handwriting in perhaps eighty cases out of a hundred. A detailed study of the cases showing inversions of judgments leads me to believe that the presence or absence of the so-called sex-signs is, in the case of any one writer, influenced largely (I) by the amount of writing done; (2) by age and consequently, to a certain extent, by practice; (3) by professional requirements such as shown by the conventional writing of grade teachers and the rapid hand of bookkeepers. As the majority of grade teachers are women and as women other than teachers as a general rule do less writing than men (professional men at least) women's writing on the average would be distinguishable from that of men.

On the face of it my results as presented are closely comparable to those obtained by Binet. Whether they are actually so could only be determined by a comparison of specimen with specimen. Particularly one would wish to compare the typical feminine and masculine hands of the two tests and above all the ambiguous hands and those showing inversion of sex signs. Such a detailed comparison would show how far the judgments passed are themselves of social origin.

My interpretation of my results would not, of course, be in 
line with the claims of professional graphologists who inspect handwriting for the discovery of such signs of femininity as lack of energy, of clearness and of simplicity, and exhibition of vanity and self-consciousness. ${ }^{1}$ On more general grounds than this one might expect a difference in the handwriting of the sexes, since previous investigations have given us reason for believing that men exceed women in motor ability. ${ }^{2}$ The application of such a general principle to sex-differences in handwriting must, however, be turned over to those psychologists who are experimentally determining the range of variation in writing reactions.

In conclusion, a word relative to the types of judgment revealed by the experiment. The varying skill shown by the subjects of the test was most interesting. The proficiency displayed by one or two of them actually gives some color to the claim of those who believe in the absoluteness of the sex-revelation in handwriting and charge error to lack of insight. On the other hand, the fact that amateurs are able to approximate the record made by professionals who have given much time and thought to the art may be cited as showing that the errors of the latter may be charged not to lack of proficiency in interpretation but to the fact that there is an easily attained limit to the power of such interpretation. Not all handwriting does reveal sex.

Binet observed that, on the whole, the ability of his subjects to give correct judgments far outran their ability to ground those judgments in definitely assigned reasons. Certain of his subjects were much more deliberate than were others who satisfied themselves with a glance of the eye. Crépieux-Jamin, on the other hand, furnished Binet with an elaborate analysis of the signs of sex discerned by him in the case of each specimen passed upon. Binet was thus furnished with a mass of material to be correlated with correct and false judgments respectively. In this respect I was unable to duplicate his test. I made, however, some attempt to determine certain facts in regard to the judgments passed.

'J. Crépieux-Jamin, L'Ecriture el le caractere, p. 385 f. 8 f.

2 H. B. Thompson, Psychological Norms in Men and Women, Chap. II., p. 
It was desired to determine, first, whether the more deliberate or the more intuitive observer would give the higher percentage of correct judgments; secondly, to note individual differences in the matter of degree of confidence, and to determine the index of accuracy with assurance.

The judgments were entered under two all-inclusive headings. Judgments Immediate and Judgments Hesitant, the observers being instructed to enter a judgment under the second head whenever there was any pause for deliberation. Under each of these headings were placed the rubrics, Confidence Great, Confidence Moderate, Confidence Slight and Confidence None. A record was kept of the time taken by each observer in passing the judgments, this record to serve as an objective check on the division made by the observer into immediate and hesitant judgments. This check was somewhat crude, inasmuch as the time might be lengthened through mechanical slowness in the recording of judgments which had been quickly passed. In general, however, the subjects giving the greater number of immediate judgments performed the test in a shorter time than the other observers. $S n$, who gave the greatest number of immediate judgments ( 89.7 per cent.), also carried out the experiment in the record time, sixty minutes. $A$, who gave the fewest immediate judgments ( 55.5 per cent.) required, with one exception, most time for the experiment, in 5 minutes.

The immediate judgment represented a judgment on the writing as a whole, with little attention to details. The judgment is simply an identification of the writing as man's or woman's or a mediate classification on the basis of some rubric, as 'bold' hence 'masculine'.

Reference to the percentage of right judgments shows that $S n$ and $R a$, who gave the highest percentages of immediate judgments, made respectively third and first place in accuracy of judgment on the whole series. $C k, B h, B$ and $P y$, who ranked third, fourth, fifth and sixth with reference to immediacy of judgment, relative to accuracy, took, respectively, the ninth, seventh, eleventh and tenth positions. On the whole, therefore, a certain amount of hesitation appears to be of advantage. 
Estimating the percentages of correct judgments for immediate and hesitant judgments, it is found, however, that with one exception, the immediate judgments give uniformly a higher percentage of correct judgments than do the hesitant. Partly, no doubt, this is due to the fact that it is the more difficult cases that induce hesitation. The subjects, however, shift their relative positions when ranked by reference to the accuracy of their immediate or hesitant judgments. Hesitation is, for certain observers, fatal, they are hopelessly confused by it. $D$ improves in her judgment; $C k$, who in other matters is quite capable of analysis and assisted thereby, appears in this test temperamentally adverse to hesitation. The hesitating judgments of $S$ are very nearly as accurate as his immediate ones. Whether, then, it is better in this test to depend upon intuition or deliberation appears to be an individual matter.

Turning now to the certainty or confidence with which judgments were given one finds again a great range of variation. The percentages of judgments given with great confidence ran from 23.5 to 82.5 per cent., the no-confidence judgments from 0 to 21.8 per cent. Three of the observers recorded only three degrees of confidence ; one confined herself to two only, namely, confidence great and confidence slight. A comparison of the percentages of correct judgments on the whole series with the percentage correct when confidence was great shows, as previously mentioned, a higher degree of accuracy when confidence is great. The individual differences are, again, notable. $D$ gives a rise in accuracy of only .5 per cent.; $P y$ gives an increase of 18.9 per cent.

A ranking of observers on the basis of their accuracy with assurance would be of prime importance if one wished to use such judgments in an objective way. Such a ranking would effect considerable shifting of relative position. $S$, who held fourth place in general accuracy with 70.5 per cent. of correct judgments, now moves to first place with a percentage of 83.3 correct judgments, an approximation of the professional record. $P y$, who held tenth place with 64 per cent. of correct judgments, now takes second place with 82.9 per cent. of correct judgments. Both $S$ and $P y$ are, however, exceedingly cautious, 
giving, respectively, only 24.3 and 23.5 per cent. of confidencegreat judgments. $R a$ and $S_{n}$ still maintain their position among the first four most accurate observers, $R a$ with a percentage of 80 . I correct judgments on 58 per cent. of confidencegreat judgments, $S n$ with $\mathbf{8 2 . 4}$ per cent. of correct judgments on 58.I per cent. of confidence-great judgments. $R a$ and $S n$ are thus seen to be altogether the most valuable subjects since their index of accuracy is high and their assurance covers a considerable range.

There was some tendency for a high percentage of confidence-great judgments to be correlated with a high percentage of immediate judgments, although the range in the latter case is less than in that of the former. In every case there are but few hesitant judgments entered under the head of confidencegreat; at most, only seven per cent. of the total number in the series.

On the whole, the individual differences thrown into relief by the test were interesting and striking. The rapidity with which some observers reached their decisions was in great contrast to the slowness of others. The variation in the assurance with which certain observers recorded their judgments contrasted with the lack of confidence exhibited by others. Noticeable, too, was the great variation in the value of the confident judgments of the different observers. One is not ready to conclude that the results of the present test would be typical of the same individual when dealing with other material, although the fact that no observer had had previous experience in passing such judgments put them, in this respect, all on the same level in the test under consideration. For all of them the test was a novel one. It may be said that the young woman giving the greatest number of great-confidence judgments $(82.5$ per cent.) bears a reputation in the college community of being confident and decided in her opinions; the one giving the lowest percentage of confidence-great judgments (23.5 per cent.) is peculiarly selfdistrustful and diffident.

Two methods of basing the judgment were described. The first method was analogical, based on vague popular inductions concerning masculine and feminine characteristics. The second 
method involved a reference to types or classes of handwriting, a more or less clear-cut classification dependent upon one's experience. The more extensive this experience and the more interest had been directed to the inspection of handwriting, the more this method prevailed. A distinct reference to one or more similar hands was often remarked. For some, this reference seemed to be to a generic rather than to a specific image. One subject who carefully reviewed her judgments with the envelopes and the list of penmen before her stated that a frequent error had been the reference of a whole class to the wrong head. Her classificatory type was clear-cut but its label 'masculine' was incorrect. How far these methods of judgment could be described as contributory, respectively, to logical or psychological certainty is not evident. Judgments given with confidence occurred in both cases. My records are not complete enough to show whether individual variations occurred in the degree of confidence accompanying these two sorts of judgment. 